\title{
The Political Impact of Science: Is Tobacco Control Science- or Policy- driven?
}

\section{Lars Thorup Larsen}

Please cite this article as:

Larsen, Lars Thorup (2008a): 'The Political Impact of Science: Is Tobacco Control Science- or Policy-driven?', Science and Public Policy, 35(10): 757-69.

DOI: 10.3152/030234208X394697

On October 8 2006, the Sunday evening news show Grand Jury on the French national channel LCl featured Prime Minister Dominique de Villepin making a bold announcement of the country's new smoking policy. Due to what he termed the "unacceptable reality" of 65,000 tobacco-related deaths per year, his government had now decided to ban smoking in public places within less than four months, while dedicated tobacco bars would be given an extra year to adapt (de Villepin, 2006), an extension later widened to include all restaurants, bars and cafés.

The smoking ban took effect in February of 2007 and although the rules in themselves are hardly different from what other European countries have implemented lately, a few things in his argument stand out as noteworthy. First of all, the sense of urgency is remarkable. Not only was the policy process extraordinarily blunt compared to most countries, but the French government even chose to implement the smoking ban by decree thereby bypassing the normal channels of parliamentary debate and decision-making. Enough has been debated, now we need to act, the Prime Minister argued (de Villepin, 2006).

Second, he argued that once having realized the unacceptable reality of these death tolls, the process of passing the decree was really only a question of "... adapting public health to necessity" (de Villepin, 2006). In this sense, new scientific facts are not only seen as one factor among others in the normal policy process, but rather as creating a state of necessity in which the element of political choice or debate is effectively annihilated.

Third, while it is very common to find smoking bans legitimated on scientific grounds, the Prime Minister's gave the argument an unusual twist by referring to the people. With this knowledge in hand, Villepin said the following day in parliament, "The French people would not understand if we do not make a decision" (Sciolino, 2006). By referring to the will of the people, he not only paid homage to the revolutionary ethos of French democracy, but he also underlined that tobacco risk is no longer just established knowledge within governmental health 
departments, but something that everyone knows, at least in this part of the World.

Finally, when asked if the same logic could be extended to alcohol regulation, Villepin lapsed quickly from necessity to laissez-faire by saying that "... we live in a free society and we can't ban everything. A lot of human activities are dangerous" (de Villepin, 2006). So even if the French smoking ban does refer to general public health arguments as we just saw, tobacco control is nevertheless seen as belonging to a different logic than the usual set of lifestyle characteristics such as alcohol, diet, and physical exercise. While the latter three are apparently subject to a political choice between freedom and regulation, tobacco risk is so great as to exclude any such choice.

\section{Science and politics}

The French discussion raises a number of interesting theoretical questions. The general issue is the relationship between scientific knowledge and public policy and although tobacco control is quite clearly an interesting case in such respect, it is less clear what theoretical approach is the most fruitful to pick.

One possible approach would be to focus on the role of knowledge in rational decision-making, which is often discussed with a normative angle on the dangers of replacing democratic influence with expert rule (Collingridge \& Reeve, 1986; cf. also Dahl, 1989). What this literature does not address so much, however, are some of the questions made obvious in the opening discussion of the French smoking ban. There seems to be a political dimension of the demand for knowledge-based decisions in tobacco control, and yet it appears as if knowledge in some situations seems to create a situation that in itself calls for immediate action, so it is difficult to take a simple point of departure in either science or politics.

Another typical approach is to delineate the historical background of the relationship between knowledge and politics, not only in the history of science and philosophy, but also in political theory. The question of philosophy and science giving advice to the prince is a long-standing affair in political theory ranging from Plato's philosopher kings through Machiavelli and Francis Bacon's famous statement 'knowledge itself is power' to its broader integration in Enlightenment philosophy (cf. Foucault, 2004: 91-113, 261-284; 2008). Another impressive literature is on the role of knowledge and science in modern state-building from the early-modern reason of state (Foucault, 2004: 243-314) to modern examples such as Weber's theory of bureaucracy, which is also about dominating through knowledge (see Wittrock, 1991; Rueschemeyer \& Skocpol, 1996). This type of historical genealogy of political knowledge would certainly add a broader perspective to the topic of science and tobacco control and perhaps clarify the cate- 
gories that politicians such as Villepin draw upon in these discussions. It is not clear, however, how the historical background can help us to address the key issue here, which is how and why knowledge or scientific evidence - in some situations but not in others - creates a demand for decisive political action to regulate the moral behavior of individual citizens.

One way to approach the irregular impact of science would be a comparative analysis. The use of cross-country comparisons is often a useful strategy to develop more qualified ideas about the importance of individual factors within a well-defined set of theoretically relevant variables. Here, we do not really have such a clear set of theoretical expectations that would make a given comparative selection of different countries or policy areas obvious. Furthermore, since tobacco control as well as tobacco knowledge have developed into highly internationalized agendas, it would be difficult at best to maintain the independence of individual cases.

Instead of the comparative approach, the strategy here is to discuss the broader development of tobacco control as a critical case of how science influences public policy. Not necessarily in the sense that it is representative of any interaction between knowledge and policy, because in some ways the struggles have been much more heated in tobacco control than in say education or health care. Tobacco control could work well as a critical case, however, for while at first sight it seems like the most clear-cut case of science-based policy, the policy process has been no less complicated for that reason.

The purpose of this article is thus to discuss the connection between science and policy-making in relation to tobacco control, but with an ambition to also contribute to the general theoretical debate about this delicate relationship. Since both two sides of the equation - tobacco-related risk knowledge and policies of tobacco control - each constitute huge areas in themselves, the strategy here is to review only what the literature on tobacco control has already said about the relationship.

The impact of knowledge upon public policy is not a simple object you can study without a theoretical lens. The purpose of this article is not to test one pregiven theory of science and politics, but rather to develop the theoretical conception of this relationship further by magnifying how academic scholars on tobacco control understand and explain it. For this reason, the article proceeds from what is strictly speaking not a 'theory' of, but rather a particular perspective on the politics of knowledge, which is a Foucauldian perspective on the 'will to knowledge' (Foucault, 1976).

In his seminal study on the history of sexuality, Foucault demonstrated how the modern conception of sexuality was facilitated by a specific 'will to knowledge' about the sex. Instead of focusing on the material object of knowledge, Foucault turned the question upside down and inquired instead how at a specific time, sexuality suddenly became the object of interest, curiousness, 
systematic scrutiny and knowledge production. Although this has often been taken to imply a completely instrumental view of knowledge, the idea is really to underline the interaction between political, societal, and scientific interests in a given object, not to reduce the latter to power in a crude sense.

On the question of tobacco, an examination of the will to knowledge means to ask why there is such a strong interest, not only among policy actors but also among academic writers - to make science count as a political argument. We might remember Foucault asking why people said with such enthusiasm that their sexuality was repressed, and in this case instead pose the analytical question: why does everyone say with such enthusiasm that new, scientific evidence is the cause of smoking bans even when this causation is obviously counter-factual? To be clear, the claim here is not that all writers on tobacco control actually say this. The point is that a theoretical focus on the will to knowledge suggests some kind of overemphasis on presenting science as the cause of policy, and the following readings of tobacco control literature should try to clarify in what sense this is the case.

Because the relationship between science and policy is currently undertheorized, it is often represented rather implicitly in the way an author explains the development of tobacco control. The following sections try to reconstruct these conceptions, but since the goal is to develop science and politics as a two-way junction, we should also discuss some of the implications and possible problems for politics of seeing it as a direct consequence of science.

Broadly speaking, one can separate two varieties of literature with respect to this question. The first variety sees tobacco control as science-driven, i.e. it views public policy as something that either follows or definitely should follow from the clear imperatives of scientific knowledge; and where tobacco control has clearly not developed so automatically, this literature tends to interpret the shortfall not as much as due to political obstacles, but typically as a result of some illegitimate interests of the tobacco industry or a lack of courage among policymakers. According to this view, tobacco control is basically a war with enemies whose complete lack of moral integrity precludes the possibility of political compromise.

The second variety of literature only sees scientific knowledge as one among many factors, while the progress of tobacco control is generally ascribed to dynamics internal to the policy process, such as agenda setting, interest group participation and institutional constraints. It views the development of tobacco control as being policy-driven, in other words. The policy-driven literature is closer to the mainstream of political science and therefore much less inclined to remove the element of political struggle from the issue.

Finally, after discussing some of problems encountered in each part of the literature, the article attempts to clarify how this case as well the Foucauldian focus on will to knowledge contributes to some of the existing literature on science 
and knowledge utilization. Does the case of tobacco control help us to develop a better understanding of the relationship and separation between science and politics?

\section{The Science-driven Literature on Tobacco Control}

The basic assertion in what I call the science-driven literature on tobacco control is the idea that documented knowledge on tobacco risk leads or should lead directly to strict political regulation of tobacco smoking. This is comparable to the French Prime Minister's view that tobacco-related mortality figures constitute a political necessity, but here with the expectation that the causation is automatic. It is also the viewpoint typically found in both national and international policy documents such as the Framework Convention on Tobacco Control, which bases it recommended regulation on the recognition that the scientific evidence against tobacco is unequivocal (WHO, 2003: 5).

The science-driven point of view is not the easiest phenomenon to document in the academic literature, however, because in many cases it mainly shows in the way an author fails to address any obstacles whatsoever between the discovery of scientific facts and political decisions. It is thus better to look at how authors reflect upon the perceived shortfalls of tobacco control. A prime example here is Roemer (2004) who gives a general overview of previous tobacco control legislation. Not only does she identify 'a smoke-free world' as the ultimate target, but she also specifies that since the legislation is "not commensurate with the risk" at present, the immediate challenge is to "... make the policy fit the science" (Roemer, 2004: 691). Although she sees an immediate association between risk knowledge and policy, it is clearly not a question of establishing some sort of balance between the two. Rather, the relationship is hierarchical in that it is the policy that needs to fit the science. Public policy is then subjected to the critical test of whether or not it is 'commensurate' with risk knowledge, but of a total ban on tobacco, it is very unclear how one is supposed to evaluate this commensurability.

Policy has a bad fit to science, this literature says, and which some contributions claim to be able to rectify by using some other set of standards to mediate between them. In the context of a general discussion on morality and health, Gostin evaluates the normative case for tobacco control and concludes that strict intervention is legitimate and morally justified as long as it is grounded in solid, scientific knowledge (Gostin, 1997: 332). Seemingly straightforward, this argument is very difficult to assess mainly because of what it chooses to ignore. Nowhere in the discussion does the question arise what else is required for intervention to be politically legitimate in the normal, democratic sense, such as the consent or participation of popular representatives. 
A more recent contribution attempts a similar strategy to Gostin by making a very thorough argument for why there is (or should be) a basic human right to tobacco control (Dresler \& Marks 2006). Like the French Minister, Dresler and Marks cite an endless line of numbers and facts on the spread of the 'tobacco epidemic' and proceed with the logical conclusion: "Tobacco control is (...) more than sound public health; it is a necessary strategy to ensure the human rights of the affected populations" (Dresler \& Marks, 2006: 650). What we should notice here is not just the quick jump from facts to norms, but also how the political arena of public health decision-making is superseded by the higher power of a claimed legal necessity.

We will return to the question of politics below, but first focus on another common issue in the science-driven literature, which is time. As the sciencedriven literature expects hard-proven facts to lead to rational policy decisions almost automatically, it becomes more difficult for these arguments to understand why this has clearly not happened already.

\section{The Problem of Timing}

A critical issue for science-driven conceptions of tobacco control is what Theodore Marmor has correctly termed 'the problem of timing' (2006: 383). As most observers notice, there is a huge time gap between firm evidence on tobaccorelated risk on one hand and effective regulation on the other. It is very common to ascribe the present wave of smoking bans to the evidence on second-hand smoke (ETS - environmentally transmitted smoke), but with twenty years between the events, it is difficult to maintain a direct relationship of cause and effect. Already in 1981 did the first studies point to a causal relationship between ETS and lung cancer, and in 1986 both the US Surgeon General, the US National Research Council and the International Agency for Research on Cancer (IARC) recognized these findings officially (Samet 2004: 289). Later studies have obviously increased the depth of our knowledge on ETS and associated it with other complications, but this does not change the basic problem that policy-wise, the timing is seriously off. With a few exceptions, it is not until the late 1990s and especially in the past five years that comprehensive tobacco control has emerged in most countries, especially in Europe (Roemer, 2004).

It is pretty obvious that the actual development of tobacco control has not followed automatically from scientific facts, a situation which makes it all the more difficult to understand why the literature has not conceptualized the intermediaries of this long process more thoroughly. Instead, there is an almost apocalyptic belief in the urgency of tobacco control in our present period, because now - with a 20-year delay - science can finally determine policy as it is supposed to. For example, a World Bank sponsored book on tobacco control argues that we live in 
an important time today, a 'watershed' (De Beyer \& Bridgen 2003: 9). Many authors have similar views, such as many contributors to the major edited volume by Boyle (2004), but we might also recall the paradoxical argument of Prime Minister Villepin here. On the one hand he said that the numbers speak for themselves, i.e. scientific facts call for action - but on the other hand he completely ignored the ironical situation that these facts have spoken the same message for 20 years. So why is he listening now?

The point is not that one can determine at what exact time science 'should' have impacted upon tobacco control, but to notice how the authors in the science-driven literature interpret the obvious gap between facts and political action. Some parts of the science-driven literature try to make sense of why the tobacco control policy process has been slow even though it is still urgent. Indicative of a very science-driven perspective, these authors explain the drawn-out process of tobacco control by referring to the tobacco industry's ability to present the evidence against tobacco as being controversial, in other words a struggle between different sets of scientific facts.

\section{The Science Wars}

Parts of the science-driven tobacco literature do not only consider knowledge to be the logical basis for political action, but see it as a weapon we should use against the tobacco industry and its lies. For instance, Michael Pertschuk boldly states that since we are at war with an opposing enemy, it is vital to have truth fighting on our side (Pertschuk, 2004: 669). It is also framed as a 'war against misinformation' (de Beyer \& Bridgen, 2003: 9) and as a fight in which both activists and political actors come 'armed with science' (Bayer \& Colgrove, 2004: 25).

The activist turn of tobacco control research is expressed very clearly in an earlier text by Pertschuk (2001). There he he says that in order to unleash the full 'power of science and truth' against the tobacco industry, it is not sufficient just to have science: You also need scientists working the field as anti-tobacco advocates (Pertschuk, 2001: 225). What began as the seemingly simple process of putting knowledge into action now turns out to be a struggle at a personal lev$\mathrm{el}$, and the tobacco industry is accused of throwing the first first stone by bringing in their own 'paid liars' as expertise (Pertschuk, 2001: 225). With the opponent already playing dirty, Pertschuk explicitly prefers not to use those scientists that are "... intoxicated with the endless recitation of arcane data", but instead he needs 'scientist advocates' who are able to "... frame the proposed regulation as moderate" (Pertschuk, 2001: 225).

This discussion recalls a long-standing debate in public health policy over the role of science in health information. A classic text here is the 1974 Lalonde report in which the Canadian health minister said that scientists should dispense 
with all the 'ifs, buts, and maybes' of scientific epistemology and instead just tell people what to do (Lalonde, 1974: 57; Larsen, 2005: 164-9). The thought of sacrificing one's academic standards in exchange for a policy goal is probably not very appealing to most scientists, but this has not stopped many of them from playing a more active role in the struggle against tobacco. In fact, this is a remarkable characteristic of the science-driven literature that even though it comprises actors from both scientific, political and NGO camps, this does not lead to as diverse arguments as one would expect. For example, the editorials of the highly esteemed British medical journal The Lancet have often made political statements with exceptional clarity. One editorial called for an immediate smoking ban in the UK by blaming tobacco deaths on the PM personally, exemplified in the not so subtle heading "How do you sleep at night, Mr. Blair?" (Lancet, 2003: 1865).

Besides urging scientists to speak out against tobacco, this literature also devotes a lot of attention to document the science-related misdeeds of the tobacco industry. Simultaneously with the US Surgeon General's report on ETS in 1986, the tobacco industry formed their own research centers for so-called 'Indoor Air Research', basically with the sole purpose of undercutting the evidence against ETS and creating controversy (Bayer \& Colgrove, 2004: 23). A similar process took place in Australia where an official recognition of ETS risk was followed by the industry's own report saying that there is "... little evidence and nothing which proves scientifically that cigarette smoke causes disease in nonsmokers" (quoted in Ballard, 2004: 105).

Throughout the 1990s, the Philip Morris Tobacco Company pursued a public relations campaign called 'sound science' and whose goal was to make ETS risk data available for the industry's own analysts to reinterpret according to corporate interests (Baba et al., 2005). Likewise, the German tobacco industry has been accused of making 'shameful science' over the course of several decades (Hirschhorn, 2000; see also Bornhaüser et al., 2006), while the newest science-based initiative from Philip Morris is met with similar skepticism (Hirschhorn et al., 2001). Finally, Proctor documents how the tobacco industry has used individual medical histories to undermine the individual claims of tobacco-related illness, which the author interprets as being an 'epidemiology of expertise' (Proctor, 2006). By making their own health research, the industry seems to have accepted the premise that today's battles over tobacco control will be settled, at least in part, in the field of science.

The battle is no longer about whether smoking is unhealthy, since the industry seems to have turned away from pure denial and adopted an allegedly more 'balanced' view on smoking. The science-driven literature obviously sees the general recognition of tobacco risk as an important step on the way to a comprehensive smoking ban, but the sudden benevolence of the tobacco industry poses problems of its own. Because the industry now acknowledges the detri- 
mental effects of tobacco use, this could make them seem more credible in making related and seemingly moderate statements about passive smoking, the usefulness of alternatives measures to smoking bans, etc. While such views are perhaps not as flatly untrue as when the industry denied everything, they might be more dangerous to the advance of tobacco control, the general view seems to be, because they present themselves as being credible and balanced.

In order to protect both science and the idea of politics based on science, this has led members of the international tobacco control community to disallow any research funding that is even remotely associated with the tobacco industry. The problem of industry-based research funding was debated fiercely in relation to the case of Enstrom and Kabat. They published an epidemiological study in the British Medical Journal in 2003, which concluded - based on the major 40year cancer prevention study of the American Cancer Society - that there was no significant causal effect between passive smoking and tobacco-related mortality (Enstrom \& Kabat, 2003). The article caused an outrage, not only because its message was so controversial, but also because the well-esteemed journal had allowed any publication by researchers who publicly declared to have received funds from tobacco-related sources (Enstrom \& Kabat, 2003: 9). In order to redeem himself, one of the authors, Dr James Enstrom of UCLA, subsequently founded the 'Scientific Integrity Institute' and accused much of the epidemiological evidence against passive smoking of being 'Lysenko pseudoscience' (Enstrom, 2007).

Disputes such as these are indications that regardless of the industry's admittance of tobacco risk, some of the political struggles over tobacco control are played out in the field of science. Much attention in the science-driven literature is devoted to track even the tiniest influence of tobacco interests upon knowledge production, for example in a journal such as Tobacco Control. From an epistemological viewpoint it is somewhat paradoxical that all parties to this controversy seem to take several conflicting roles with respect to the status of science and politics. All of them praise the laurels of scientific truth and integrity in high terms and accuse their opponents of polluting science with interests, political or economic; and yet, several of these writers also seem willing to sacrifice a certain amount of scientific facticity in exchange for reaching their respective objectives be it profit or strict health promotion laws. Apparently, this literature often frames the discussion of tobacco control as being something beyond the scope of politics, such as a confrontation between friends and enemies. As the final characteristic of the science-driven tobacco literature, the next section considers this tendency to redress political conflicts in the form of a moral division between good and evil.

\section{The antipolitics of science-driven policy development}


It is basically an old discussion whether a strong dependence on scientific expertise in political systems can lead to a democratic deficit, because technocratic expert influence takes the place of public deliberation. Paul Feyerabend, for one, calls science a threat to democracy with reference to this conflict (Feyerabend, 1978: 76). The French Prime Minister's argument expressed a highly centralized version of this problem, because he chose to dispense parliamentary debate by decree simply because the facts were so overwhelming. Although related to this problem, the following discussion concerns a similar part of the science-driven argument that tends to extract any sign of political discussion from tobacco control. It does not necessarily lead to a complete absence of democratic debate, but to an ardent moral framing of smokers - active and passive - as being the victims of the tobacco industry as the supreme evil.

As Leichter and others describe, the evolution of tobacco control is partly synonymous with a fierce struggle against the tobacco industry whose continued profits from selling lethal drugs have given them names like the merchants of death' (Larry White quoted in Leichter, 1991: 97). Some commentators have even compared the misdeeds of the tobacco industry to both the holocaust and nuclear weapons (see Leichter, 1991: 97), and often the science-driven literature portrays the industry as being enemies beyond the scope of negotiation and compromise. The question is what political implications follow from this type of adversarial framing.

Within contemporary political theory there is a growing interest in antipolitical arguments (Schedler, 1997; Weltmann \& Billig, 2001; Hay, 2007). Antipolitics is when a controversy is framed as being beyond the normal parameters of politics typically because the adversary is characterized as being corrupt, illegitimate or in other senses beyond moral reach. These are just characterizations, of course, because at the heart, these conflicts are indeed highly political even if some actors claim them selves or the present to be beyond politics. Although the tone varies, the science-driven literature generally characterizes the tobacco industry as being morally corrupt to the extent that political negotiation or compromise becomes futile. One of the more extreme voices whose arguments typically extract the political element from tobacco control is C. Everett Koop, former U.S. Surgeon General who initiated the 1986 report that first recognized ETS as potentially lethal:

"It is clear that the motivation of Big Tobacco is greed. I believe greed that flourishes at the expense of the destruction of millions of lives every year can only be described as evil; it cannot be reconciled with personal and corporate ethics and morality. Such greed is infectious and pervasive (...) President Reagan called the Soviet Union 'the evil empire', and President George W. Bush referred to Iraq, Iran, and North Korea as 'the axis of evil'. 
Yet these entities to whom evils were attributed have not killed more than 400.000 citizens of the United States, or millions worldwide, each year. The evil empire is Big Tobacco and unlike military and political enemies who say, 'I intend to kill you if I can', Big Tobacco disguises its evil with the invitation to light up and become alive with pleasure" (Koop, 2004: xii).

Outside of vulgar Marxism, it is rare to find an entire business characterized as fundamentally evil. Unlike categories such as 'problematic', 'wrong' or 'bad', the word evil is almost never used in the language of politics with the exception of the few foreign policy examples mentioned in the quote. The word evil denotes willingly hurting others to an extent where the evildoer is beyond repair. The last sentence in the quotation adds the final stone to a deep antipolitical argument, seeing as it puts the tobacco industry one step below murderers by associating its willful killing with a sense of pleasure and satisfaction. This is what is normally known as sadism.

It is pretty clear that what is described here is not so much a policy process as it is a war in which some objects are sacred while the enemies are evil. The ultimate point, however, is not just that these authors frame the industry as evil, but rather that science plays a key role in this antipolitical argument. It is worth to mention that Koop is quoted here not from a dedicated policy document, but from his preface to Oxford University Press' 800-page volume of state-of-theart tobacco knowledge. It is reasonable, then, to assume that the editors see a relatively tight connection between the facts to values of tobacco control, a connection that seems to leave very little room for political discussion or compromise. Science is seen as having an active and even crucial role in the war against tobacco, such as when Pertschuk speaks of a war with an opposing enemy and with truth fighting on our side (2004: 669), or when Koop characterizes his surgeon general's position against tobacco as guided by scientific truth and motivated by justice and service to humanity (2004: xv). There is a potential connection, in other words, between seeing public policy as science-driven on the one hand and using this automatic relationship as a vehicle for antipolitical arguments on the other.

There is another side to the antipolitics of the science-driven literature, which has to do not with framing the tobacco industry, but with how we see smokers. It is not uncommon to find smokers characterized either as sinners or as victims, and the latter category is most interesting here. Victims of smoking are generally worthy of help, but typically on the premise that since their dependence keeps them from making rational decisions themselves, others should make the tough calls on their behalf. This is difficult in modern democracies where the victims are also citizens, because while politicians are expected to help the former with a certain amount of paternalism, they are also expected to listen to the latter and respect their opinions. 
One of the things that make political discussions on tobacco control particularly difficult is precisely this duality where citizens are both objects and subjects at the same time. If you say that smokers are nothing but helpless victims of a fierce battle between science and a reckless industry, you also somehow lose respect for their integrity as responsible citizens. This accentuates a general tension in public health policy between the ambition to make citizens more responsible for their own health behavior on the one hand and the unwillingness to accept some of their unhealthy choices on the other hand (Larsen, 2005: 174). As the similar argument of Howard Leichter goes, making citizens responsible for their own health also means giving them freedom to be foolish (1991). The point here is that reducing smokers to helpless victims also means depriving them of some of their political authority, hence the antipolitical nature of this type of framing.

This is where the science-driven view on public policy reaches its epitome, because the imperatives of putting knowledge into action become so resilient as to ignore how citizens might want to set the limits of public health intervention. The claim is not that democracy actually works this way, only that several authors in the science-driven literature happen to reconstruct tobacco control in a way where facts speak for themselves and by the same token they lose interest in what citizens actually think.

Not all parts of the science-driven literature take the argument this far, since there are many variations of what is clearly a normative perspective on the impact of science. The science-driven literature on tobacco control contains many descriptive elements as well. If any conflict or tension should emerge between the normative and the descriptive dimensions, this literature appears to maintain the normative expectation that under the right set of circumstances scientific facts should be the driving force of rational policy.

\section{The policy-driven literature on tobacco control}

A separate but comparatively smaller literature has emerged within mainstream political science and although it contains several different views on what governs the policy process, the relationship between science and public policy is typically seen as much less automatic than in the former. This other literature focuses on the dynamics and institutional surroundings of public policy, but unfortunately this also means there is less literature to review, because these authors do not write very much on the influence of scientific knowledge. By not addressing the relationship between science and policy as directly, it is still somehow taken for granted in this literature, although in a less automatic fashion. Some of the same problems as we have seen already turn up again in the policy-driven literature, such as the problem of how to account for the time gap between the emergence 
of tobacco-related risk knowledge and the introduction of severe political intervention.

\section{Timing in a policy-driven dynamic}

It is interesting to notice how the same historical events are subject to highly different interpretations depending on the particular perspective. This is very much the issue here, because the first reports about the risks of ETS did not appear in a political vacuum. They responded to political struggles in the new public health movement in place well before 1986. The health risk of passive smoking was, as Virginia Berridge ironically writes, a "scientific fact waiting to emerge" (Berridge, 2004: 124). Already in the 1970s had anti-tobacco organizations such as the British Action on Smoking and Health (ASH) begun to demand intervention against passive smoking armed with arguments about rights and protection against nuisance (Berridge, 2004: 124; cf. Feldman \& Bayer, 2004a: 293). There was a definite demand for knowledge saying that ETS was risky. Although this was clearly countered by strong interests in proving tobacco innocent, it goes to show that the political struggle over passive smoking was not caused single-handedly by scientific facts. So, even though the recent development of tobacco control indicates a time gap between knowledge and politics, this does not involve an earlier 'golden age' when rational policies sprang spontaneously from the honorable fountains of scientific knowledge.

It is not that knowledge plays no part in policy development at all. Several authors rightly point to the centrality of knowledge in the broader 'culture shift' surrounding ETS, a shift that changed the overall public image of smoking, smokers and the tobacco industry from positive or balanced into an exclusively negative one (Brandt, 2004: 262; cf. also Baumgartner \& Jones, 1993: 91). Thus, the key point in the policy-driven literature is not that knowledge plays no part in tobacco control, but that it is just one factor among many other policy deteminants and one that needs a political interpretation to have a policy effect. The defining characteristic of the policy-driven literature on tobacco control is precisely that it puts the main theoretical focus on the internal dynamics of the policy process even in the event of new scientific discoveries.

A good example of a policy-driven focus on timing is Studlar's work, which separates the development of tobacco control into five phases between the late $19^{\text {th }}$ century and the present (Studlar, 2002: 25-40). What appears to be decisive in the shifts from one phase to another is not the emergence of facts in itself, but the way in which both facts and the culture shift are incorporated by political authorities as well as by social movements working against big tobacco.

A similar focus on timing exists in the tobacco control literature that draws on theories of agenda setting (Studlar, 2002; Albæk et al., 2007; Princen \& Rhi- 
nard, 2007). Although tobacco control could provide us with a classical example of what Kingdon terms 'idea whose time has come' (Kingdon, 1984: 1), most of this literature draws on Baumgartner and Jones' version of agenda setting theory (1993). Their original book actually uses tobacco as a core example of a change in policy monopoly. Several measures of shifts in public attention document the shift in tone and choice of topics from positive to negative (Baumgartner \& Jones, 1993: 91, 109-17), which is basically what was previously referred to as the culture shift around tobacco. Another key part of their argument is that the shift in policy monopolies on tobacco control is also mobilized through a venue shift. While most congressional hearings on tobacco previously took place in committes related to agriculture who are likely to focus on its positive sides, it is now mainly being discussed in health-related committees with a much more negative view on tobacco (Baumgartner \& Jones, 1993: 209-10).

In a very broad sense, Baumgartner and Jones' theory of agenda setting and punctuated equilibrium seems to fit the case of tobacco pretty well, because of the focus on long periods of stability followed by short periods of major policy change. It is not entirely clear, perhaps, how the shift in both the tone and venue of attention to tobacco ultimately leads to a substantial change in tobacco control on the level of actual policy instruments. In most countries, the attention of both the public and of policy-relevant venues had shifted from positive to negative way before the recent wave of smokefree legislation. The ability to explain the major changes and dynamics of the policy process may come at the expense of explaining specific instances of policy change, although this is in fact attempted in more recent contributions such as Princen and Rhinard (2007).

Another limitation of the agenda setting perspective, which is even more important here is that it only considers the impact of science in a very indirect form. For example, Baumgartner and Jones quote an argument from Bernard Cohen saying that scientific controversies are often exaggerated in mediated public debate, because it gives the impression of a balanced presentation of the topic (Baumgartner \& Jones, 1993: 119). This would indicate that scientific knowledge can not only lead to policy change, but also stall a possible change. Aside from this, the theory's expectation seems to be that knowledge can affect the policy process indirectly by either shifting the general tone of an issue or by getting the attention of policy-makers in a relevant policy venue. This is another way of saying that there are no specific conditions for the impact of science in the agenda setting perspective as opposed to any other set of policy ideas that someone tries to get on the policy agenda, and the general conditions under which it can have an effect are largely determined by the internal dynamics of policy subsystems and mediated public attention.

\section{Delays and obstacles}


Rather than explain the actual impact of knowledge upon public policy, what the policy-driven literature on tobacco control often does instead is to explain the comparative variation in policy development by referring to various delays and obstacles, typically of a political or institutional character. Indicative of this difference is Wendy Parmet's review of Martha Derthick's book Up in Smoke about the litigation procedures against big tobacco (Parmet, 2006). It strikes Parmet as odd that Derthick portrays the tobacco wars as a purely political contest between interest groups, which means that the facts - the mortality and morbidity of tobacco use - have little or no relevance in the matter (Parmet, 2006: 386). Obviously, this is only worth mentioning if one is under the impression that scientific facts should be decisive, a group to which Parmet apparently belongs while Derthick does not.

Two of the more comprehensive contributions on the politics of tobacco control make similar observations. Studlar concludes a broad assessment of tobacco control and policy change by saying that a "... simple model of science transferred to policy in this area is too simplistic, given delays in time and crosscountry variation in policy adoption" (Studlar, 2007: 21). Similarly, the collaborative work Unfiltered edited by Feldman and Bayer concludes that science and evidence "... influence but do not determine public policy" (Feldman \& Bayer, 2004: 293). Both these quotations leave the impression that in a sense, we should expect to find a more direct relation between science and public policy were it not for the obstacles of the policy process.

It does not mean that these writers take the same normative edge on the lacking impact of science as we saw in the science-driven literature, because the policy-driven literature on tobacco control generally has a descriptive approach to the issue trying to understand how it works and not how it should work. Both Studlar's and Feldman and Bayer's observations should be read in this light. While both the quoted passages provide us with reasonable descriptive accounts of the somewhat limited impact of science on policy, it does not tell us what influence to expect in the first place. The political science literature on tobacco control does little to theorize the translation or conversion process of putting knowledge into policy decisions. What precise dynamics are in fact obstructed by the many obstacles and internal dynamics of political systems?

Some political science analyses of tobacco control ascribe the delays and variation in policy change to factors that have little to do with the impact of scientific facts. A prime example here is the comparative study by Marmor and Lieberman, who finds federalism to be a determinant of strong tobacco control regimes because it provides many access points for anti-tobacco interest groups influence (Marmor \& Lieberman, 2004: 289; Marmor, 2006: 382). The importance of social movements is analyzed more directly in the work of Nathanson who use the strategies of anti-tobacco groups to explain variation in policy change (2005). 
The decisive factor for policy change in Nathanson's view is the social movements' construction of tobacco as a credible health risk, and while the perception of risk may draw upon scientific sources, it depends more upon ideology than science in practice where the perception of credible risk often precedes actual knowledge (Nathanson, 1999: 479).

Other analysts explain the variation by referring to concepts such as policy learning, transfer, diffusion, emulation, epistemic communities, etc. (Studlar, 2006; 2007; Brandt, 2004). These concepts emphasize various ways in which policy ideas travel between countries, but it varies a lot to what extent these ideas are only policy instruments or if they really represent a specific way of thinking. Brandt's analysis emphasizes diffusion of ideas, but less so for knowledge than for the shifting cultural norms about where and for whom smoking is seen as appropriate (2004).

The comparative analysis by Studlar initially puts the focus on the transfer of policy instruments in the strict sense, but includes some discussion about the travel of ideas and information in itself (2006: 383-4). For example, the tobaccorelated reports from the US Surgeon General and the UK Royal College of Physicians seem to have become points of reference for tobacco control policies way beyond their countries of origin. Also, anti-tobacco NGOs have played and continue to play an active role in establishing a constant flow of tobacco-related risk knowledge into most Western countries, obviously with the aim of getting national actors to lobby for a stronger regulation of tobacco use. In these studies, there seems to be some room for analyzing and even measuring the varying impact of knowledge, but on the premise that nothing specific separates the role of science in this respect from any other set of policy-relevant ideas.

In general, the policy-driven literature on tobacco control analyzes the time gap in tobacco control as a result of obstacles or delays that political systems will set for just about any external input, not just scientific knowledge. The focus on obstacles gives a more accurate descriptive representation of the time gap and the many inconsistencies of an overly linear view of science and public policy.

On the other hand, these policy theories only do what they were designed to do, i.e. to theorize and analyze the dynamics of the policy process. In this sense, even if this literature gives a more credible account of the policy process around tobacco, it still seems to leave intact an underlying theoretical assumption of a linear relationship between knowledge and politics were it not for the properties of the policy process. Hence, we do not yet know how knowledge would impact public policy in situations that could not be blamed on the structural inertia of political systems. In the concluding part of the article, a brief attempt is made to begin this theoretical discussion and connect the previous observations on science and tobacco control with a few insights from the general literature on science and public policy. 


\section{Conclusion}

The previous discussion has accentuated the need for a better theory of how scientific knowledge interacts with decision-making processes in public policy. If we take into account that tobacco is an issue where the facts have been both relatively clear and bearing serious human consequences, it is remarkable how underdeveloped the interaction between the two regimes really is. The concluding section begins with a few observations of what we can be learned from the points where the two literatures clash and then proceeds to connect these observations with the broader theoretical questions about the separation between science and politics.

It is interesting how differently the two literatures conceptualize the policy impact of knowledge, or rather, even though neither of them really conceptualizes the relationship, they both have implicit understandings of what it is about. In the science-driven literature on tobacco control, there is an implicit understanding that tobacco bans follow from undisputable scientific facts. The strange thing is, of course, that this has clearly not happened, which creates a peculiar ambivalence in the science-driven literature between urgency and delay. The facts are so overwhelming that severe steps against tobacco should be imminent, the argument goes, but due to the deceitful dealings of Big Tobacco, we keep on waiting for the tobacco-free society to emerge. The policy-driven literature gives similar attention to the timing of tobacco control, but since political science has a ready arsenal of theories about the obstacles of the policy process, the time lag causes less confusion here. As already mentioned, this does not explain why scientific facts do turn into political decisions eventually, so we are still left with an undertheorized relationship of science to politics.

Comparing the two literatures, another peculiar difference spring to mind. It seems clear that many authors in the science-driven literature see themselves more as policy activists than it is the case with the political scientists in the second half. It is paradoxical that the scholars who believe that science speaks for itself are also the ones who find it most compelling to speak on its behalf in terms of being involved in anti-tobacco advocacy work. The more esoteric political science literature has a much more distant relationship to practice and produces knowledge about tobacco control for knowledge's own sake. Another way to characterize this split is to underline the normative character of the sciencedriven literature and the descriptive purpose of the policy literature. The classical dichotomy between normative and descriptive approaches does not really exhaust the complexities of the two literatures, however, in particular because the science-driven literature constantly conflates the two. 
Not only the role of science, but also the politics of tobacco control is conceptualized very differently across these two types of literature. Again, it is mainly the position of the science-driven literature that is ambivalent. As we have just seen, scholars in this literature believe that knowledge should be used to reach the policy objectives of anti-tobacco even if sometimes this goal comes at the expense of scientific purity. On the contrary, the science-driven literature also has clear affinities with antipolitical arguments where the usual workings of political dispute are dispensed in favor of decisions based on fact. One could argue that policy-driven authors do not focus much on the democratic dimensions either, but still it is a long way from separating the political world into good and evil.

It is also interesting to notice here that the antipolitical inclinations of the science-driven literature are quite different from the classical way in which scholars have seen science as the end of politics. A classic problematic is whether science will replace politics with expertise or if the advance of science would foster a broader decline of politics in society (Dahl, 1989; Albæk, 1995; Lane, 1966; Bell, 1976; Lindblom, 1990: 213-4; Redner, 2001). On the issue of tobacco control, science does not lead to a depoliticized society, but rather to an intensified moral dispute, which we should not forget is still deeply political despite the presentation as being in opposition thereto.

A third aspect of the antipolitics in tobacco control was discovered with respect to the ambiguous position of the people, who are seen as both victims and villains at the same time. The relationship between government and the people is ambiguous in any circumstance, because while the French Prime Minister said that his people demanded government action in response to irrefutable facts, a large proportion of the same people continues to ignore health information on a daily basis. Saying that the people demand action is also a way of removing the question of tobacco control from the normal parameters of politics where people may have conflicting and even contradictory opinions on where to draw the line between freedom and health protection. In this case, the equivalence between knowledge and political action is established by annihilating the controversy and ambivalence of the latter.

Turning to the theoretical discussion, we should begin by reassessing the initial question about the 'will to knowledge' around tobacco control. Do we now know why science is so often presented with great enthusiasm as the treadstone of political action? At least we now see different shades of enthusiasm given the reservations of the policy-driven literature, but generally the 'will' seems to drape public policies in a coat of neutrality and absolute urgency. Most significant is perhaps the tendency to employ the will to knowledge as a means to replace a situation of messy, political controversy with a clear moral stand to save human lives.

This does not mean, however, that the will to present science as the cause of action only functions for proponents of stricter smoking policies, be- 
cause we have also seen how the allusion of scientific controversy can be used to block policy change. This process is similar to discussions about climate change and global environmental problems (Ehrlich and Ehrlich, 1996) as well as to some general observations in the knowledge utilization literature (Cohen quoted in Baumgartner and Jones, 1993: 119). The point is that no singular policy directive follows from presenting science as an externally given reason, because the function of such a will to knowledge is 'tactically polyvalent' as originally termed by Foucault (1976: 132).

The two literatures on tobacco control each have a tendency to reduce science and politics to the other. Not in the same sense as Lindblom and Cohen's classical observation that policy making often leaves both suppliers and users of knowledge dissatisfied because one part does not listen while the other does not hear what he wants to listen to (1979: 1). Here, the conflict is not just between different interpretations of the same facts or the same political decisions. It is in the conceptions of the field of science and politics respectively that these two literatures each reduce the other. The science-driven literature bluntly reduces a controversial political question to the crudest form of scientism. The policy-driven literature, on the other hand, does not sacrifice politics for science, but it quickly reduces knowledge to just another input factor, which does not enlighten us why it should be any different from policies driven (or not driven) by say culture, religion or the media. What we need is a theoretical conception of the relationship between knowledge and public policy that analyzes the interaction and interdependence of each type of social phenomenon, but without depriving each of its own proprietary complexities and controversies.

There are several ways to conceptualize the division between the fields of science and politics. Many scholars in the present literature on science and public policy approach this division by analyzing and describing some of the empirical situations in which science and politics meet. For example, Grunwald (2006) examines the importance of scientific independence for appearing trustworthy in parliamentary technology assessments, while both Braun (2008) and Slipersæter et al. (2007) analyze the impact and responsiveness to science and politics in several countries' research and innovation policies.

The theoretical underpinning of these and related studies (see also Leinhos, 2005; Waterton, 2005) is often some version of the Latour-inspired focus on 'boundary work', 'boundary objects' and 'boundary organizations' (see Raman, 2005; Guston, 2001). The main idea is that the boundaries between science and non-science are not given by the basic parameters of epistemology, such as in the classic idea of demarcation of science. Instead, the boundaries have to be maintained by scientists doing boundary work or designated organizations designed to administer the boundaries of what can be called scientific (Guston, 2001: 399). 
Although the boundary perspective is perhaps less developed on the side of politics, it contributes to the present discussion by effectively rejecting the basic premises of arcane scientism. The reason we should reject the scientism as theoretical lens is not that science or knowledge is bad, but that both scientism and the critique of science have become mundane observations in both society and political disputes (Latour, 2004), which stands out with surprising clarity in the conflicts over tobacco.

However, the blurring of the old division between science and nonscience - for example politics - does not necessarily mean that no separation can exist between the two fields. The present study has demonstrated the existence of two quite separated perspectives on the same development of tobacco control. This does not suggest a general 'blurring' of boundaries, but perhaps the need is for a different theoretical conception of the differentiation of science from politics.

The article has drawn upon and maintains Foucault's idea of the will to knowledge as the key lens to understand the complex interaction between science and policy. It would be possible, though, to expand the Foucauldian perspective with some insights not only from the boundary literature, but also from Niklas Luhmann's systems theory (1994). Luhmann argues that society's subsystems such as politics and science are functionally differentiated and operationally closed. Science can still reproduce its own boundary even after the fall of old world scientism, but at the same time it has lost the ability to instruct other functional systems such as politics about what to do (Luhmann, 1994: 20). While systems such as science and politics are operationally closed from each other, they are nevertheless cognitively open and thus able to communicate about science in the political system and about politics in the scientific system.

Perhaps this is precisely what we see in the case of tobacco control and science? Politicians such as the French Prime Minister can use old world scientism to legitimize a blunt, political decision on tobacco while some scientists can turn to political arguments when trying to settle a heated scientific debate about the dangers of smoking. 


\section{REFERENCES}

Albæk, Erik 1995. Between knowledge and power: Utilization of social science in public policy making. Policy Sciences, 28, 79-100.

Albæk, Erik, Christoffer Green-Pedersen and Lars Beer Nielsen 2007. Making Tobacco Control a Political Issue in the United States and Denmark: The Dynamics of Issue Expansion in Comparative Perspective. Journal of Comparative Policy Research, 9 (forthcoming).

Baba, Annamaria et al. 2005, Legislating 'Sound Science': The Role of the To-

bacco Industry. American Journal of Public Health, 95 (Supplement 1), S20-S27. Ballard, John 2004. The Politics of Tobacco Control in Australia. In Unfiltered. Conflicts over Tobacco Policy and Public Health, eds. Eric A Feldman and Ronald Bayer, pp. 89-113. Cambridge MA: Harvard University Press.

Baumgartner, Frank and Bryan D Jones 1993. Agendas and Instability in American Politics. Chicago IL: University of Chicago Press.

Bayer, Ronald and James Colgrove 2004. Children and Bystanders first: The Ethics and Politics of Tobacco Control in the United States. In Unfiltered. Conflicts over Tobacco Policy and Public Health, eds. Eric A Feldman and Ronald Bayer, pp. 8-37. Cambridge MA: Harvard University Press.

Bell, Daniel 1976. The Coming of Post-Industrial Society: A Venture in Social Forecasting. New York NY: Basic Books.

Berridge, Virginia 2004. Militants, Manufacturers, and Governments: Postwar Smoking Policy in the United Kingdom. In Unfiltered. Conflicts over Tobacco Policy and Public Health, eds. Eric A Feldman and Ronald Bayer, pp. 114-137. Cambridge MA: Harvard University Press.

de Beyer, Joy and Linda Waverly Brigden 2003. Tobacco Control Policy. Strategies, Successes, and Setbacks. Washington DC: The International Bank for Reconstruction and Development.

Bornhaüser, A, J McCarthy and S A Glantz 2006. German tobacco industry's successful efforts to maintain scientific and political respectability to prevent regulation of secondhand smoke. Tobacco Control, 15(2).

Boyle, Peter et al. eds. 2004. Tobacco - Science, Policy and Public Health. Oxford: Oxford University Press.

Brandt, Allan M 2004. Difference and Diffusion: Cross-Cultural Perspectives on the Rise of Anti-Tobacco Policies. In Unfiltered. Conflicts over Tobacco Policy and Public Health, eds. Eric A Feldman and Ronald Bayer, pp. 255-74. Cambridge MA: Harvard University Press.

Braun, Dietmar 2008. Lessons on the political coordination of knowledge and innovation policies. Science and Public Policy, 35(4), 289-298.

Collingridge, David and Colin Reeve 1986. Science Speaks to Power. The Role of Experts in Policy Making. London: Frances Pinter.

Dahl, Robert A 1989. Democracy and its Critics. New Haven CT: Yale University Press.

Dresler, Carolyn and Stephen Marks 2006. The Emerging Human Right to Tobacco Control. Human Rights Quarterly, 28, 599-651. 
Ehrlich, Paul R and Anne H Ehrlich 1996. Betrayal of Science and Reason. How Anti-Environmental Rhetoric Threatens Our Future. Washington DC: Island Press.

Enstrom, James E 2007. Defending legitimate epidemiological research: combating Lysenko pseudoscience. Epidemiologic Perspectives and Innovations, 4(11). James E Enstrom and Geoffrey C Kabat 2003. Environmental tobacco smoke and tobacco related mortality in a prospective study of Californians, 1960-98. British Medical Journal, 326, 1057.

Feldman, Eric A and Ronald Bayer 2004. Conclusion. Lessons from the Comparative Study of Tobacco Control. In Unfiltered. Conflicts over Tobacco Policy and Public Health, pp. 292-307. Cambridge MA: Harvard University Press.

Feyerabend, Paul 1978. Science in a Free Society. London: Verso.

Foucault, Michel 1976. Histoire de la sexualité 1: la volonté de savoir. Paris: Gallimard.

Foucault, Michel 2004. Sécurité, territoire, population. Cours au Collège de France 1977-78. Paris: Gallimard/Seuil.

Foucault, Michel 2008. Le gouvernement de soi et des autres. Cours au Collège de France 1982-1983. Paris: Gallimard/Seuil.

Gostin, Lawrence 1997. The Legal Regulation of Smoking (and Smokers): Public Health or Secular Morality. In Morality and Health, eds. Allan M Brandt and Paul Rozin, pp. 331-357. London: Routledge.

Grunwald, Armin 2006. Scientific independence as a constitutive part of parliamentary technology assessment. Science and Public Policy, 33(2), 103-13.

Guston, David H 2001. Boundary Organizations in Environmental Policy and Science: An Introduction. Science, Technology and Human Values, 26(4), 399-408. Hay, Colin 2007. Why We Hate Politics. London: Polity Press.

Hirschhorn, Norbert 2000. Shameful science: four decades of the German tobacco industry's hidden research on smoking and health. Tobacco Control, 9, 24248.

Hirschhorn, Norbert et al. 2001. Philip Morris' new scientific initiative: an analysis. Tobacco Control, 10(3), 247-52.

Kingdon, John W 1984. Agendas, Alternatives and Public Policies. New York NY: Harper Collins.

Koop, Everett C 2004. Preface. Tobacco: The public health disaster of the twentieth century. In Tobacco - Science, Policy and Public Health, eds. Peter Boyle et al., pp. v-xvii. Oxford: Oxford University Press.

Lalonde, Marc 1974. A New Perspective on the Health of Canadians. A Working Document. Ottawa: Government of Canada. Minister of Supply and Services. Lancet, the 2003. Editorial: How do you sleep at night, Mr Blair? The Lancet, 362(9399), 1865.

Lane, Robert E 1966. The Decline of Politics and Ideology in a Knowledgeable Society.

American Sociological Review, 31(5), 649-62.

Larsen, Lars Thorup 2005. 'The Truth Will Set You Free': A Genealogy of Danish and American Public Health Policy 1975-2005. PhD-dissertation, Department of Political Science, University of Aarhus.

Latour, Bruno 2004. Why Has Critique Run Out of Steam? From Matters of Fact to Matters of Concern. Critical Inquiry, 30, 225-48. 
Leichter, Howard M 1991. Free to be Foolish. Politics and Health Promotion in the United States and Great Britain. Princeton NJ: Princeton University Press. Leinhos, Mary 2005. The US National Bioethics Advisory Commission as a boundary organization. Science and Public Policy, 32(6), 423-33.

Lindblom, Charles E 1990. Inquiry and change. The troubled attempt to understand and shape society. New Haven CT: Yale University Press.

Lindblom, Charles E and David K Cohen 1979. Usable Knowledge. Social Science and Social Problem Solving. New Haven CT: Yale University Press.

Luhmann, Niklas 1994. The Modernity of Science. New German Critique, 61, 923.

Marmor, Theodore R 2006. Review essay. Book Review Symposium on the Politics of Tobacco. Journal of Health Politics, Policy and Law, 31(2), 375-84.

Marmor, Theodore R and Evan S Lieberman 2004. Tobacco Control in Comparative Perspective: Eight Nations in Search of an Explanation. In Unfiltered. Conflicts over Tobacco Policy and Public Health, eds. Eric A Feldman and Ronald Bayer, pp. 275-91. Cambridge MA: Harvard University Press.

Nathanson, Constance A 1999. Social Movements as Catalysts for Policy Change: The Case of Smoking and Guns. Journal of Health Politics, Policy and Law, 24(3), 421-88.

Nathanson, Constance A 2005. Collective Actors and Corporate Targets in Tobacco Control: A Cross-National Comparison. Health Education and Behavior, 32(3), 337-54.

Parmet, Wendy E 2006. Review essay. Book Review Symposium on the Politics of Tobacco. Journal of Health Politics, Policy and Law, 31(2), 385-93.

Pertschuk, Michael 2001. The power of science and truth: countering paid liars' efforts to influence tobacco policy. Tobacco Control, 10, 225-6.

Pertschuk, Michael 2004. Lessons in tobacco control advocacy leadership. In Tobacco - Science, Policy and Public Health, eds. Peter Boyle et al., pp. 669-75. Oxford: Oxford University Press.

Princen, Sebastiaan and Mark Rhinard 2007. Crashing and creeping: agendasetting dynamics in the European Union. Journal of European Public Policy, 13(7), 1119-32.

Proctor, Robert N 2006. 'Everyone knew but no one had proof': tobacco industry use of medical history expertise in US courts, 1990-2002. Tobacco Control, 15(supplement IV), IV117-IV125.

Raman, Sujatha 2005. Institutional perspectives on science-policy boundaries. Science and Public Policy, 32(6), 418-22.

Redner, Harry 2001. Science and politics: a critique of scientistic conceptions of knowledge and society. Social Science Information, 40(4), 515-44.

Roemer, Ruth 2004. A brief history of legislation to control the tobacco epidemic. In Tobacco - Science, Policy and Public Health, eds. Peter Boyle et al., pp. 67794. Oxford: Oxford University Press.

Samet, Jonathan M 2004. Passive Smoking and Health. In Tobacco - Science, Policy and Public Health, eds. Peter Boyle et al., pp. 287-313. Oxford: Oxford University Press.

Schedler, Andreas 1997. The End of Politics? Explorations into Modern Antipolitics. London: Macmillan. 
Sciolino, Elaine 2006. Smoking no longer très chic in France. New York Times, October 82006.

Slipersæter, Stig, Benedetto Lepori and Michael Dinges 2007. Between policy and science: research councils' responsiveness in Austria, Norway and Switzerland. Science and Public Policy, 34(6), 401-15.

Studlar, Donley T 2002. Tobacco Control. Comparative Politics in the United States and Canada. Peterborough ON: Broadview Press.

Studlar, Donley T 2006. Tobacco Control Policy Instruments in a Shrinking World: How Much Policy Learning? International Journal of Public Administration, 29, 367-96.

Studlar, Donley T 2007. What Explains Policy Change in Tobacco Control Policy in Advanced Industrial Democracies? Working paper, Department of Political Science, University of Aarhus.

Rueschemeyer, Dietrich and Theda Skocpol eds. 1996. States, social knowledge, and the origins of modern social policies. Princeton NJ: Princeton University Press.

de Villepin, Dominique 2006. Intervention du Premier Ministre du 8 octobre 2006. Interview on 'Grand Jury' - LCI/RTL/Le Figaro. URL (consulted March 2007) http://www.tabac.gouv.fr/article.php?id_article=192

Waterton, Claire 2005. Scientists' conceptions of the boundaries between their own research and policy. Science and Public Policy, 32(6), 435-44.

Weltmann, David and Michael Billig 2001. The Political Psychology of Contemporary Anti-Politics: A Discursive Approach to the End-of-Ideology Era. Political Psychology, 22(2), 367-82.

WHO 2003. Framework Convention on Tobacco Control. Geneva: World Health Organization.

Wittrock, Björn 1991. Social knowledge and public policy: eight models of interaction. In Social Sciences and Modern States. National Experiences and Theoretical Crossroads, eds. Peter Wagner et al., pp. 333-53. Cambridge: Cambridge University Press. 